\title{
Avaliação do conhecimento e comportamento dos pacientes da Universidade da Cidade de São Paulo sobre a Doença Periodontal
}

\section{Evaluation of the knowledge and behavior of patients at the University of the City of São Paulo about Periodontal Disease.}

\section{RESUMO}

O objetivo do estudo foi avaliar o nível de conhecimento e instrução de higiene bucal e mecanismos de prevenção previamente adquiridas de indivíduos ingressantes pela primeira vez à Clínica da Faculdade de Odontologia da Universidade Cidade de São Paulo sobre a doença periodontal provenientes do cirurgião dentista. A análise foi realizada por meio de um questionário estruturado. Após responderem, foram orientados sobre a doença periodontal, bem como a sua prevenção. Foram avaliados 94 pacientes adultos entre 18 e 80 anos e os dados submetidos à análise estatística descritiva. Para participar da pesquisa era necessário ter ido previamente ao cirurgiãodentista. Os resultados mostraram que 55,32\% dos pacientes eram do gênero feminino, sendo predominante a faixa etária entre 45 a 60 anos. Escova e dentifrício foram os recursos mais utilizados para higienização bucal por $76,60 \%$ dos entrevistados. $\mathrm{O}$ percentual $60,64 \%$ dos pacientes alegaram nunca ter recebido orientação da maneira correta do uso do fio dental e 70,72\% não tiveram a orientação do que é gengivite/ periodontite advindas do cirurgião-dentista. O fio dental não é utilizado por $42,55 \%$ dos entrevistados, sendo $39,36 \%$ afirmaram que não utilizam porque não sabem. Pôdese concluir que os pacientes avaliados apresentam um conhecimento desigual sobre a prevenção da doença periodontal. Existe a necessidade contínua de orientação sobre as medidas preventivas para a doença periodontal, ressaltando o papel da utilização do fio dental pelo cirurgião dentista e nos programas educativos.

Palavras-chave: Doença periodontal, Prevenção, Educação em saúde bucal.

\begin{abstract}
The objective of this study was to evaluate the percentage of individuals entering for the first time to the Clinic of the School of Dentistry, University of São Paulo, has enough information to prevent periodontal disease coming from the dentist. This analysis was done through a specific questionnaire and after answering, they were oriented about the periodontal disease, as well as its prevention. Ninety-four adult patients between 18 and 80 years old were evaluated and data submitted to descriptive statistical analysis. To participate in the research it was necessary to have gone to the dentist. The results showed that $55.32 \%$ of the patients were female, with a predominance of the age group between 45 and 60 years. Toothbrush and toothpaste were the most used resources for oral hygiene by $76.60 \%$ of respondents. The number corresponding to $60.64 \%$ claimed that they never received guidance on the correct way of flossing and $70.72 \%$ did not have the orientation of what is gingivitis / periodontitis coming from the dentist. Flossing is not used by $42.55 \%$ of respondents, and $39.36 \%$ claimed they do not use because they do not know. It was concluded that the evaluated patients present unequal knowledge about the prevention of periodontal disease. There is a continuing need for guidance on preventive measures for periodontal disease, highlighting the role of dental flossing and educational programs.
\end{abstract}

Keywords: Periodontal disease, Prevention, Oral health education.
Nathali Bragner dos Santos ${ }^{1}$

Bruna DiProfio ${ }^{2}$

Tarcila Triviño

1 Aluna do Curso de graduação em Odontologia, Universidade Cidade de São Paulo.

${ }^{2}$ DDS, MsC. Professor Curso de lato sensu em Odontologia, Universidade Cidade de São Paulo.

${ }^{3} \mathrm{DDS}, \mathrm{MsC}$, PhD. Professor Curso de lato sensu em Odontologia, Universidade Cidade de São Paulo.

Autor para correspondência:

Nome do autor: Tarcila Triviño

Endereço: Avenida Nove de Julho, 5483, conj

111 - Jardim Paulista - São Paulo - CEP

01407-200

Telefone: (11) 981961120 


\section{INTRODUÇÃO}

A gengivite e periodontite crônica representam um dos grandes problemas de saúde pública, devido sua prevalência relativamente alta até mesmo nos países desenvolvidos. É considerada a doença crônica que afeta a dentição humana com maior incidência; sendo a segunda afecção mais prevalente na cavidade bucal ${ }^{1}$.

No Brasil, a periodontite afeta aproximadamente $79 \%$ da população. Sua maior frequência ocorre entre os indivíduos de faixas etárias mais avançadas, com prevalência de $90 \%$ no grupo de brasileiros com idade entre 45 e 49 anos ${ }^{2}$.

A gengivite induzida por placa é definida como condição inflamatória sítio específica multifatorial iniciada pelo acúmulo de biofilme ou placa bacteriana, restrita a gengiva que não se estende ao periodonto de sustentação. Trata-se de uma condição reversível, preditora do desenvolvimento e progressão da periodontite, caracterizada por edema, sangramento gengival, eritema, desconforto à sondagem, escovação ou mastigação, alterações de paladar, halitose, redução da saúde bucal e qualidade de vida, na ausência de histórico prévio de periodontite. Pode ocorrer em periodonto íntegro, periodonto reduzido (não acometido por periodontite) e inflamação gengival em casos de periodontite não controlada. A desordem é clinicamente classificada como localizada, quando o sangramento à sondagem está presente entre $10 \%$ e $30 \%$, generalizada com sangramento presente em mais de $30 \%$ dos sítios e ausência de doença diante de menos de $10 \%$ dos sítios com sangramento ${ }^{1,3}$.

A periodontite é uma doença inflamatória multifatorial crônica associada a disbiose bacteriana e é caracterizada pela destruição progressiva da inserção periodontal ${ }^{4}$. Caraterizada clinicamente pela perda de inserção clínica, presença de bolsas periodontias (aumento da profundidade clínica de sondagem), sangramento à sondagem e radiograficamente pela perda óssea alveolar ${ }^{4}$. Apresenta como fatores de risco, além do microbioma periodontopatogênico, gênero, idade, fatores socioeconômicos, susceptibilidade genética, estilo de vida, fatores comportamentais (como o tabagismo ou mesmo o etilismo), comorbidades locais (xerostomia) e sistêmicas (como a diabetes mellitus) e estado nutricional ${ }^{5}$ É classificada segundo estádios, através da análise de severidade (perda de inserção clínica e de perda óssea) e complexidade (controle da doença, função e estética); graus que consideram evidências e antecipam o risco de progressão futura da doença (direta avaliando a perda óssea ao histórico pregresso de perda e indireta correlacionando a perda à idade); ainda, segundo a extensão e distribuição (localizada até 30\% dos sítios, generalizada mais que 30\% dos sítios e padrão incisivo/molar) ${ }^{6}$. A compreensão da natureza da doença é crucial para a pesquisa e desenvolvimento de promoção da saúde, prevenção e tratamento mais eficazes ${ }^{4}$.

A efetiva remoção e desorganização regular do acúmulo de depósito bacteriano é um componente primordial da prevenção e controle de doenças periodontais induzidas por placa bacteriana. Diante da inabilidade do paciente em alcançar o controle ideal, a intervenção profissional se torna imprescindível. A prevenção consiste na inibição do desenvolvimento, progressão e recorrência da inflamação gengival clinicamente detectável. Atrelada ao tratamento periodontal compõe fatores críticos e componentes básicos da prevenção e controle das doenças periodontais. Além disso, o gerenciamento de fatores de risco como tabagismo e diabetes constitui uma parte importante da prevenção, controle e manejo das doenças periodontais ${ }^{1,3}$

As instruções de higiene bucal consistem na educação dos pacientes sobre o cuidado com a saúde bucal e conscientizá-los sobre a importância da realização regular de modo a manter a saúde periodontal ${ }^{3}$. É fundamental que se destaque a importância da comunicação profissional/paciente para o sucesso do tratamento odontológico. 
As orientações devem ser reforçadas rotineiramente em pacientes com doenças periodontais. As orientações devem ser reforçadas rotineiramente em pacientes com doenças periodontais ${ }^{7}$ No entanto, a literatura não é contundente quanto à técnicas de instrução e sobre sua eficácia clínica específica, uma vez que a redução dos escores de placa bacteriana e sangramento ao longo do tempo não foram observados ${ }^{7}$ Programas de motivação e educação em higiene bucal através de métodos simples e eficientes para desorganização biofilme dental e prevenção das doenças bucais são essenciais no intuito de se alcançar uma melhor qualidade da saúde bucal ${ }^{8-12}$.

O objetivo deste estudo foi avaliar o grau de informação sobre higiene bucal e prevenção da doença periodontal de pacientes que procuram pela primeira vez por atendimento odontológico na Universidade Cidade de São Paulo advindas do cirurgião dentista.

\section{MÉTODO}

Este estudo foi avaliado e aprovado pelo Comitê de Ética em Pesquisa sob número de protocolo 3.422.857PH/CEP, conforme Resolução 196/96 do Conselho Nacional de Saúde. Foram avaliados, mediante um questionário, o total de 94 pacientes adultos, 94\% do público alvo, de ambos os gêneros, com idade entre 18 a 80 anos, que ingressaram pela primeira vez no atendimento da Clínica Escola da Faculdade de Odontologia da Universidade Cidade de São Paulo. O questionário foi elaborado com perguntas diretas para facilitar a compreensão pelos pacientes e contribuir para a clareza das informações. Previamente à aplicação do questionário, os participantes foram informados sobre os objetivos do estudo, assinaram o termo de concedimento e as dúvidas esclarecidas. As questões foram respondidas de forma voluntária e individual, sendo que o paciente poderia solicitar seu desligamento do estudo a qualquer momento. Após o preenchimento do questionário, todos os pacientes receberam uma escova dental macia, instrução de escovação, uso de fio dental e conhecimentos sobre a doença periodontal. Os dados obtidos por meio do questionário foram avaliados e seus resultados analisados estatisticamente (estatística descritiva).

\section{RESULTADOS}

Os resultados dos questionários foram expressos pela frequência de distribuições e computados em porcentagens, demonstrados em tabelas e gráficos.

Figura 1 - Distribuição dos pacientes de acordo com o gênero (feminino ou masculino).

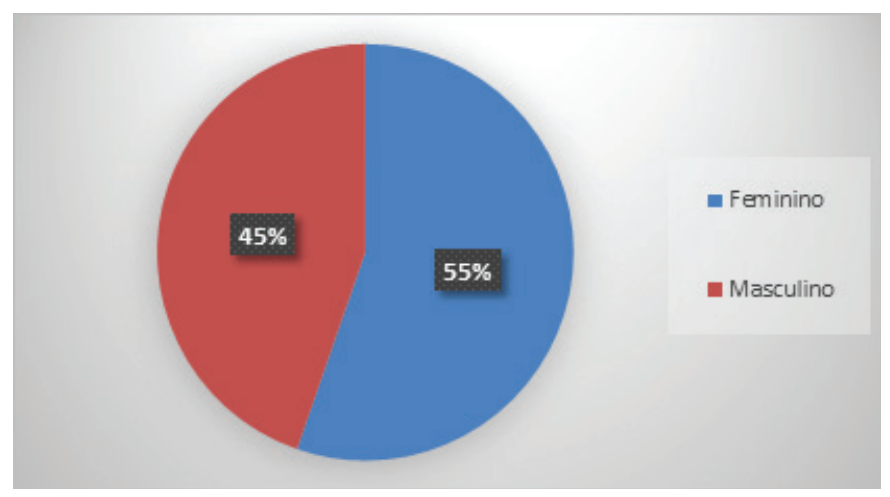


Com relação aos pacientes avaliados, constatou-se que 52 (55,32\%) eram do gênero feminino e $42(44,68 \%)$ do masculino (Figura 1), sendo predominante a faixa etária entre 44 a 60 anos (Tabela 1).

\begin{tabular}{|lcc|}
\hline \multicolumn{3}{|c|}{ Tabela 1 } \\
Relação entre faixa etária e número de pacientes entrevistados \\
\multicolumn{1}{l}{ Idade } & Número de pacientes & Frequência (\%) \\
18 a 25 & 6 & 6,38 \\
25 a 35 & 14 & 14,89 \\
35 a 45 & 13 & 13,83 \\
45 a 60 & 35 & 37,23 \\
Mais de 60 & 26 & 27,66 \\
Total & 94 & 100 \\
\hline
\end{tabular}

A Tabela 2 mostra o perfil dos pacientes avaliados em relação ao nível de escolaridade. Trinta e oito $(40,43 \%)$ apresentam ensino médio completo e $22(23,41)$ ensino superior completo.

\begin{tabular}{|lcc|}
\hline \multicolumn{3}{|c|}{ Tabela 2} \\
Relação entre nível de escolaridade e número de pacientes \\
entrevistados & Número de pacientes & Frequência (\%) \\
\hline Escolaridade & & \\
\hline & 12 & 12,77 \\
Ensino fundamental incompleto & 12 & 12,77 \\
Ensino fundamental completo & 12 & 10,64 \\
Ensino médio incompleto & 10 & 40,43 \\
Ensino médio completo & 38 & 23,41 \\
Ensino superior & 22 & \\
Total & 94 & \\
\hline
\end{tabular}


Os resultados apresentados no Quadro 1 mostram que mais da metade da amostra não tinham conhecimentos prévios orientados pelo cirurgião dentista sobre a técnica de escovação adequada 55,32\%, sobre o uso do fio dental 60,64\%. 78,72\% não sabiam o significado de gengivite/periodontite.

\section{Quadro 1}

Distribuição das respostas ao questionário aplicado de acordo com orientação recebida advinda do cirurgião dentista aos pacientes atendidos.

\begin{tabular}{|c|c|c|c|}
\hline Perguntas & Sim & Não & Não lembro \\
\hline Você já foi ao cirurgião dentista? & $94(100 \%)$ & $0(0 \%)$ & $0(0 \%)$ \\
\hline $\begin{array}{l}\text { Você já foi orientado por um cirurgião dentista sobre a } \\
\text { maneira correta da escovação bucal? }\end{array}$ & $42(44,68 \%)$ & $52(55,32 \%)$ & $0(0 \%)$ \\
\hline $\begin{array}{l}\text { Você já foi orientado por um cirurgião dentista sobre a } \\
\text { importância do uso do fio dental? }\end{array}$ & $52(55,32 \%)$ & $41(43,62 \%)$ & $1(1,06 \%)$ \\
\hline $\begin{array}{l}\text { Você já foi orientado por um cirurgião dentista sobre a } \\
\text { maneira correta de utilizar o fio dental? }\end{array}$ & $35(37,23 \%)$ & $57 \quad(60,64 \%)$ & $2(2,13 \%)$ \\
\hline $\begin{array}{l}\text { Você já foi orientado por um cirurgião dentista sobre o } \\
\text { que é gengivite/periodontite? }\end{array}$ & $15(15,96 \%)$ & $74(78,72 \%)$ & $5(5,32 \%)$ \\
\hline
\end{tabular}

Quadro 2

Distribuição das respostas ao questionário aplicado quanto às informações relacionadas ao conhecimento e comportamento em saúde bucal

\begin{tabular}{|c|c|c|}
\hline \multirow{2}{*}{\begin{tabular}{|l|} 
Questões/respostas \\
O que motivou a sua procura ao serviço odontológico da faculdade?
\end{tabular}} & $\mathbf{n}$ & Frequência \\
\hline & & \\
\hline Motivos estéticos & 26 & 27,66 \\
\hline Dor & 18 & 19,15 \\
\hline Consulta de rotina & 22 & 25,53 \\
\hline Problemas gengivais & 7 & 7,45 \\
\hline Recomendações de outros profissionais & 10 & 10,64 \\
\hline Outros & 9 & 9,57 \\
\hline Total & 94 & 100 \\
\hline Por que você acha que as pessoas perdem os dentes? & & \\
\hline Não cuidam & 53 & 56,38 \\
\hline Genética/dentes fracos & 11 & 11,7 \\
\hline Não têm informação & 19 & 20,21 \\
\hline Cárie & 3 & 3,19 \\
\hline Doença Periodontal & 2 & 2,13 \\
\hline Não sei & 5 & 5,32 \\
\hline Total & 94 & 100 \\
\hline Geralmente você utiliza para a higiene oral: & & \\
\hline Escova e pasta & 72 & 76,66 \\
\hline Escova, pasta e fio dental & 18 & 19,15 \\
\hline Escova, pasta, fio dental e enxaguante bucal & 4 & 4,26 \\
\hline Total & 94 & 100 \\
\hline Quantas vezes você utiliza o fio dental por dia? & & \\
\hline Nenhuma & 40 & 42,55 \\
\hline 1 & 31 & 32,98 \\
\hline 2 & 10 & 10,64 \\
\hline 3 ou mais & 13 & 13,83 \\
\hline Total & 94 & 100 \\
\hline Qual a maior dificuldade que você encontra parra passar o fio dental? & & \\
\hline Não sei & 37 & 39,36 \\
\hline Não tenho tempo & 6 & 6,38 \\
\hline Não tenho condições financeiras & 5 & 5,32 \\
\hline Nenhuma & 46 & 48,94 \\
\hline Total & 94 & 100 \\
\hline
\end{tabular}


Figura 2 - Quando foi sua última visita ao cirurgião dentista



No Quadro 2, quando questionados sobre o principal motivo da sua procura ao serviço odontológico da universidade 26 pacientes $(27,66 \%)$ afirmaram que foram motivos estéticos e $22(25,53 \%)$ mencionaram consulta de rotina. Questionados sobre a causa das perdas dos dentes 53 (56,38\%) responderam que o motivo foi a falta de cuidado e 19 $(20,21 \%)$ por falta de informação. Na higiene bucal, a maioria respondeu que utilizava constantemente escova e pasta 72 (76,66\%). Sobre a utilização diária do fio dental, 40 pacientes $(42,55 \%)$ responderam que não utilizavam. Na dificuldade encontrada para o uso do mesmo $37(39,36 \%)$ alegaram o desconhecimento do uso.

Na figura 2, o tempo estimado da última consulta com o cirurgião dentista, observou-se que 34 pacientes (36,17\%) relataram que foi a mais de 3 anos e $25(26,6 \%)$ de 6 meses a 1 ano, $18(19,15 \%)$ de 0 a 6 meses, $17(18,09 \%) 1$ a 3 anos.

\section{DISCUSS ÃO}

A maioria dos entrevistados relataram nível escolar de ensino médio e superior e visita prévia ao cirurgião dentista o intervalo menor que 3 anos. Isso demostra que possuem conhecimento e acesso ao serviço odontológico.

Quando questionados sobre as orientações concedidas do cirurgião dentista, 60,64\% dos pacientes alegaram que nunca receberam orientação sobre a maneira correta do uso do fio dental, 70,72\% não tiveram a orientação do que é gengivite/periodontite. Sobre a importância do uso do fio dental, cerca de 43,62\% dos entrevistados não tiveram essa explicação provenientes do mesmo profissional e 55,32\% não tiveram a orientação da maneira correta da escovação dental. A maior parte das queixas dos pacientes foi a estética $(27,66 \%)$. Na higiene bucal, a maioria respondeu que faziam o uso constante de escova e pasta $72(76,66 \%)$. O fio dental não era utilizado por $42,55 \%$ dos entrevistados, sendo que $39,36 \%$ alegaram que não utilizam porque não sabiam.

Estas amostras mostram que os pacientes avaliados receberam nível de orientação diferentes. Mesmo possuindo nível escolar e acesso aos serviços odontológicos, faltou a informação para a prevenção da doença periodontal. 
Nascimento et al $^{8}$ avaliaram a autopercepção em pacientes com periodontite em atendimento na Clínica de Periodontia. Quando perguntados sobre qual doença os pacientes eram portadores 53,84\% não sabiam. Em relação à diferença entre gengivite e periodontite, apenas 21 (53,84\%) sabiam a diferença. Concluíram, através dos dados coletados, que ainda há carência de conhecimentos mais específicos sobre a doença periodontal, sendo assim, essa questão precisa receber mais atenção por parte dos responsáveis pelo tratamento, no caso, os alunos de graduação.

Bardal et al ${ }^{9}$ verificaram os efeitos de ações educativas, preventivas e motivacionais sobre a saúde bucal de pacientes em tratamento ortodôntico fixo. Os participantes receberam instruções sobre higiene bucal e reforçaram no decorrer dos 6 meses da pesquisa. Foram realizados exames clínicos em 6, 12 e 24 semanas, para verificação dos índices de Placa, Gengival e Sangramento. Os resultados mostraram que as condições de saúde bucal dos participantes, inicialmente insatisfatórias, melhoraram significativamente no decorrer do estudo, considerando-se todos os índices. As ações preventivas, educativas e motivacionais realizadas foram estatisticamente eficazes na melhora da saúde bucal dos pacientes ortodônticos. Concluíram que a promoção de saúde e a prevenção de doenças devem fazer parte do atendimento que os ortodontistas direcionam aos seus pacientes, sendo que a orientação e motivação quanto aos cuidados com a saúde bucal devem estar presentes antes e durante o tratamento.

Chou et al ${ }^{13}$ avaliaram o conhecimento e comportamento dos pacientes em tratamento odontológico em relação à cárie, doença periodontal. Foram avaliados 430 pacientes adultos com idade entre 18 e 80 anos. Os resultados mostraram que fio dental foram utilizados por $43,95 \%$ dos entrevistados, sendo $46,05 \%$ não o utilizavam alegando que o mesmo provoca sangramento gengival. Contraditoriamente, $87,90 \%$ disseram que já receberam orientação de higiene e 70,93\% foram orientado pelo cirurgião dentista. Os participantes com maior nível de escolaridade apresentaram mais conhecimento sobre cárie e doença periodontal. Escova e dentifrício foram os recursos mais utilizados para higienização bucal por $56,05 \%$ dos entrevistados. No mesmo estudo quando os pacientes foram questionados sobre o principal motivo da sua procura ao serviço odontológico da universidade a presença de dor $(53,03 \%)$ foi o fator que motivou a procura pelo atendimento odontológico.

A prevenção é apontada como o melhor tratamento, mas ainda é pouco abortado e utilizado na área odontológica. Os serviços de saúde bucal têm como base o tratamento restaurador-reabilitador. A doença periodontal precisa de uma conscientização por parte dos pacientes, essa conscientização é de extrema importância, pois o tratamento não depende somente dos procedimentos realizados no consultório ${ }^{14}$.

Muitos pacientes não têm acesso à informação adequada da importância dos conhecimentos básicos para ter autonomia de cuidar da saúde bucal. No próprio tratamento não conseguem entender o real significado e prognóstico, para que se mantenham incentivados a colaborar ${ }^{14}$.

Entre os brasileiros com mais de 18 anos que buscaram atendimento de saúde bucal 74,3\% recorreram a consultórios particulares ${ }^{2}$. Isto justifica o porquê a educação em saúde precisa advir do profissional com maior interesse para a promoção e recuperação da saúde bucal.

O Brasil tem $11 \%$ da sua população edêntula, o que corresponde a 16 milhões de pessoas ${ }^{2}$. Sabendo-se que o avanço da periodontite é a perda dental e que sua única for- 
ma de prevenção é a higiene bucal, o conhecimento da correta higiene bucal, abrangendo técnica de escovação, fio de dental e dentifrício adequado, pode e deve ser abordada nas consultas de rotina a fim de se evitar tratamentos mais invasivos como a extração dental.

Eke et al ${ }^{15}$ descreveram a prevalência, gravidade e extensão da periodontite em adultos americanos utilizando dados combinados dos ciclos de 2009 a 2010 e 2011 a 2012 do National Health e Inquérito de Exame Nutricional (NHANES). Como métodos utilizaram as estimativas que foram derivadas para adultos dentados, com idade $\geq 30$ anos, de civis americanos não-população institucionalizada. A periodontite foi definida por combinações de perda de inserção clínica e profundidade de sondagem periodontal de seis locais por dente em todos os dentes, exceto os terceiros molares, usando definições de casos de vigilância. Segundo os resultados de 2009 a 2012, 46\% dos adultos dos EUA, 64,7 milhões de pessoas apresentam periodontite.

As práticas de saúde, cuja forma ainda hegemônica de ações curativas de caráter individual, mostram-se ineficazes para a doença periodontal. Neste contexto, a Odontologia nas últimas décadas, vem sendo repensada, levando à mudança no paradigma da prática da profissão em vários países ${ }^{10}$.

Pinheiro et al ${ }^{16}$ discutiram a produção acadêmica no Brasil sobre a formação do cirurgião dentista. Observou-se a mudança na formação do cirurgião dentista, apontando a necessidade de alterações curriculares e o ensino voltado para as necessidades sociais, bem como a integração ensino-serviço. De 1992 a 2005 foi constatada a tendência de uma formação predominantemente tecnicista e curativa. Discorreram sobre a necessidade de uma transformação da Odontologia mais voltada para as necessidades da população, assumindo, portanto, caráter mais social com ênfase na promoção de saúde. Tal caráter social da Odontologia adequa-se perfeitamente à realidade brasileira e atende às exigências da Lei de Diretrizes e Bases da Educação Nacional de 1996 e das Diretrizes Curriculares Nacionais, assim como integra os cirurgiões-dentistas à realidade do Programa Saúde da Família.

A forma tradicional de tratamento, centrada na doença, está gradualmente cedendo espaço para outro tipo de atenção profissional, cuja ideologia é a prevenção das enfermidades e a promoção de saúde. Pode-se concluir com base nestas considerações, que este modelo de atenção à saúde bucal, vigente até então na maioria das instituições de saúde bucal, pode ter suas origens vinculadas, em grande parte, à formação desses profissionais, uma vez que essa formação é fundamentada ainda num modelo de ensino que valoriza mais as ciências básicas do que os aspectos de promoção e prevenção ${ }^{16}$.

Nas últimas décadas enormes volumes financeiros alocados para o tratamento de doenças como cárie e patologias periodontais não produziam resultados satisfatórios, apresentando pouco impacto epidemiológico, baixa cobertura e desigualdades no acesso. Pesquisas passaram a se concentrar na área, iniciando, também, estudos sobre a proposta educacional do curso de Odontologia ${ }^{16}$.

Estudos reforçam que o processo educativo é fundamental, pois indivíduos bem instruídos têm uma melhor percepção de sua condição bucal, participam mais ativamente do tratamento e tendem a realizar uma melhor higiene bucal ${ }^{8-12}$.

Enfatiza-se neste estudo que a odontologia pode ser sim uma profissão com perfeição técnica e inovadora, mas também, ser uma odontologia preventiva, com atendimento 
humanizado, passando informações, ensinando o autocuidado para esses pacientes, visando proporcionar saúde bucal e qualidade de vida.

\section{CONCLUSÕES}

De acordo com a metodologia empregada e com os resultados obtidos, pôde-se concluir que:

- os pacientes avaliados apresentaram nível de orientação desigual sobre a doença periodontal e higiene bucal;

- há importância desta orientação preventiva advinda de um cirurgião dentista.

- existe a necessidade contínua de orientação sobre as medidas preventivas para a doença periodontal, ressaltando o da utilização do fio dental, orientação de higiene nas consultas de rotinas e nos programas educativos.

\section{REFERÊNCIAS}

1. Chapple ILC. Mealey BL. Van Dyke TE. Bartold M. Dommisch H. Eickholz P. et al. Periodontal health and gingival diseases and conditions on an intact and a reduced periodontium: Consensus report of workgroup 1 of the 2017 World Workshop on the Classification of Periodontal and Peri-Implant Diseases and Conditions. J Periodontol 2018; 89(1):74-84

2. Minitério da Saúde [homepage na internet]. Pesquisa Nacional de Saúde Bucal 2012, [acesso em 27 jun 2019]. Disponível em: http://bvsms.saude.gov.br/bvs/publicacoes/ pesquisa_nacional_saude_bucal.pdf

3. Trombelli L, Farina R, Silva CO, Tatakis DN. Gengivite induzida por placa: definição e diagnóstico de casos considerações. J Clin Periodontol 2018;45 (20):44-67.

4. Papapanou PN, Sanz M, et al. Periodontitis: Consensus report of Workgroup 2 of the 2017 World Workshop on the Classification of Periodontal and Peri-Implant Diseases and Conditions. J Periodontol 2018;89(1):173-82.

5. Needleman I, Garcia R, Gkarias N, et al. Mean anual attchmetbone level and tooth loss: a systematic review. J Clin Periodontol 2018;45(20):112-29.

6. Holzhausen M, França BN, Gasparoni LM, Rebeis ES, Saraiva L, Villar CC, Pannuti CM, Romito GA. Sistema de classificação das doenças e condições periodontais [Internet]. São Paulo:Faculdade de Odontologia da USP; 2019.

7. Carra MC, Detzen L, Kitzmann J, Woelber JP, Ramseier CA, Bouchard P. Promoting behavioural changes to improve oral hygiene in patients with periodontal diseases: a systematic review. J Clin Periodontol.[periódico da Internet], 2020 Jan [acesso em 15 jun 2020]. Disponível em: https://doi.org/10.1111/jcpe.13234.

8. Nascimento MC, Barbosa LA, Nobre C, Novaes MR, Bittencourt S. avaliação da autopercepção em pacientes com periodontite crônica- estudo piloto. Int J 2011;10(3):154-60.

9. Bardal PAP, Olympio KPK, Bastos JRM, Henriques JFC, Buzalaf MAR. Educação e motivação em saúde bucal - prevenindo doenças e promovendo saúde em pacientes sob tratamento ortodôntico. Dental Press J Orthod 2011;16(3):95-102.

10. Bastos JA, Vilela EM, Henrique MN, Daibert PC, Fernandes LFMC, Paula DAAET, et al. avaliação do conhecimento sobre doença periodontal em uma amostra de nefrologistas e enfermeiros que atuam com doença renal crônica pré-dialítica. J Bras Nefrol 2011;33(4):431-5.

11. Barbosa CC, Morais PLS, Mattos FF. conhecimentos e práticas sobre as principais doenças bucais da população adulta que demanda centro de saúde. HU Rev 2009;35(4):274-80. 
12. Carvalho ES, Bastos RS, Rodrigues ADM, Mello WM, Lauris JRP, Bastos FRM, Carvalho SH, PeresIet S. Epidemiologia das doenças bucais em indivíduos na faixa etária entre 35 e 44 anos: o cenário epidemiológico do trabalhador. RGO 2010;58(1):109-14.

13. Chou TTA, Ferreira NS, Kubo CH, Silva EG, Huhtala MFRL, Gonçalves EP, Gomes APM. Avaliação do conhecimento e comportamento dos pacientes em tratamento odontológico em relação à cárie, doença periodontal. RPG Rev Pós Grad. 2011;18(3):140-7.

14. Murray JJ. Bases para a Prevenção das doenças Bucais (OMS) Genebra, Livraria Santos Editora, 1992.

15. Eke PI, Dye BA, Wei L, Slade GD, Thornton-Evans GO, Borgnakke WS et la. Update on Prevalence of Periodontitis in Adults in the United States. J Periodontol 2015;86(5):611-22.

16. Pinheiro FMC, Nóbrega-herrien SM, Almeida MEL, Almeida MI. a formação do cirurgião-dentista no brasil: contribuições de estudos para a prática da profissão RGO 2009;57(1):99-106.

17. Tonetti MS, Eickholz P, Loos BG, Papapanou P, van der Velden U, Armitage G, Princípios na prevenção de relatório periodontais doenças Consenso do grupo 1 da 11 a oficina Europeia em periodontologia para prevenção eficaz de doenças periodontais e peri-implantares. J Clin Periodontol 2015;42(16):5-11.

18. Murakami S, Mealey BL, Mariotti A, Chapple ILC. Dental plaque-induced gingival conditions. J Periodontol 2018;89(1):17-27. 